\title{
O-N-S Self-Doped Hierarchical Porous Carbon Synthesized from Lotus Leaves with High Performance for Dye Adsorption
}

\author{
Huan Liu,* Chao Xu, Yiming Ren, Dingxing Tang, Cuige Zhang, Fang Li, Xueling Wei, Chaofei Huo,
} Xingyang Li, and Rongli Zhang

Cite This: ACS Omega 2020, 5, 27032-27042

Read Online

ABSTRACT: Three-dimensional porous carbon was fabricated using lotus leaves as a renewable precursor. The as-synthesized carbon had a high surface area (3601 $\mathrm{m}^{2} / \mathrm{g}$ ), suitable $\mathrm{O}-\mathrm{N}-\mathrm{S}$ self-doping, and three-dimensional (3D) architecture with interconnected micro/meso/macropores, together with proper pore size distribution. Consequently, these admirable features endowed porous carbon as a superadsorbent for dye removal with ultrahigh adsorption capacity for rhodamine B $(9444.39 \mathrm{mg} / \mathrm{g})$ and reliable cyclability (>97\% capacitance retention after 10 cycles). The adsorption of dye onto the as-prepared carbon was a spontaneous endothermic process and followed the pseudo-second-order kinetic model and the Langmuir isotherm model. The $\pi-\pi$ stacking, hydrogen bond, and acid-base interactions were proposed to mainly account for the combination of the adsorbate and the adsorbent. Overall, these values indicated the high-performance biomass-derived carbon as a dye adsorbent and may boost the large-scale production and application of $3 \mathrm{D}$ hierarchical porous carbon with heteroatom doping in the field of wastewater treatment.

\section{INTRODUCTION}

With the express growth of the world economy and the fast expansion of industrial production, the deterioration of environment continually accelerates, particularly, water pollution including the contamination of surface and underground water resources. Because of the extensive application of dyes in paper, plastic, rubber, textile, leather, cosmetic, glass, and pharmaceutical industries, the discharge of dye-containing industrial sewage not only leads to rise of toxicity and chemical oxygen demand but also weakens light penetration, greatly retarding the photosynthetic phenomena of the hydrophyte and the growth of microbes and hence bringing about the accumulation of impurities in water. ${ }^{1-6}$ It is easily confirmed whether the water is contaminated by industrial dye or not because of the visibility of the dye even at $\sim 0.005 \mathrm{ppm}^{7}$ Among dyestuffs, rhodamine $\mathrm{B}(\mathrm{RhB})$, as a typical cationic dye, has carcinogenic and mutagenic influences on humans and animals. Therefore, the rapid and efficient removal of $\mathrm{RhB}$ from wastewater has attracted increasing attention over the past years.

Adsorption technology is widely used to purify dyecontaining wastewater because of its low cost and easy handling characteristics. Porous carbon is regarded as a prospective adsorbent for the adsorption of various organic compounds because of its large surface area, well-developed porous structure, excellent chemical stability, and easy regeneration. $^{8-13}$ Particularly, owing to its abundance, being
$\mathrm{CO}_{2}$ neutral, and fast growth, biomass-derived carbon has been proven to be an attractive alternative for dye adsorption. ${ }^{10,14,15}$ To improve the adsorption performance of carbon materials for organic dyes, many researchers have spared no effort to synthesize carbon-based adsorbents with the properties mentioned below: (1) high surface area to offer abundant adsorption sites; (2) three-dimensional (3D) hierarchical porous structure with interconnected $\mathrm{micro} / \mathrm{meso} /$ macropores to boost dye molecule transportation by shortening the diffusion pathway and enhancing the mechanical stability as well; and (3) heteroatom doping (i.e., O, N, S, and P) to enhance the wettability to increase pore accessibility and electrostatic interaction between the adsorbent and the adsorbate via hydrogen bond or/and acid-base interactions to consolidate the adsorption of adsorbate molecules onto the adsorbent surface. ${ }^{16-20}$ So far, the carbon materials with these features were usually synthesized by applying a certain amount of hard template for the production of hierarchical porous structure and applying nitrogen-, sulfur- and phosphoruscontaining chemical reagents for the doping of heteroatoms

Received: May 1, 2020

Accepted: August 13, 2020

Published: October 14, 2020 

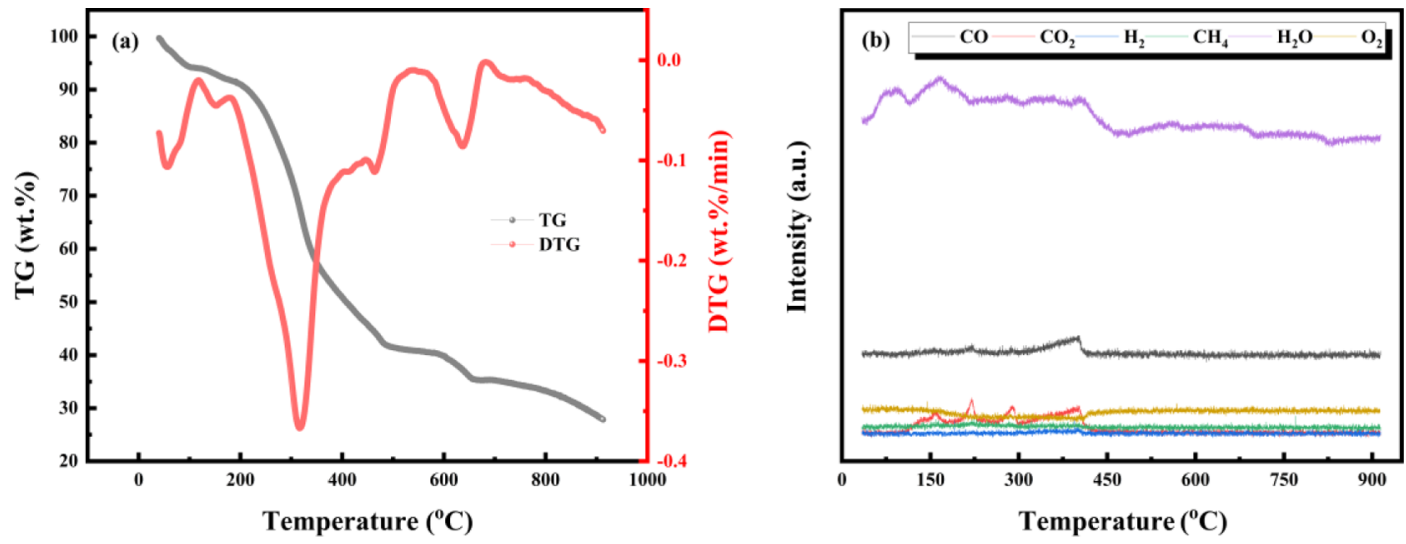

Figure 1. (a) TG and differential TG curves of lotus leaves. (b) Mass spectrum of TG-MS analyses.

(e.g., O, N, S, and P). ${ }^{21-27}$ Therefore, the production procedure was often complex, time-consuming, and unfriendly to the environment, which heavily restricted the development and utilization of these kind of carbon materials. Consequently, it would be a significantly promising way to directly prepare hierarchical porous carbon with heteroatom self-doping from renewable biomass as the precursor without the utilization of any other reagents.

The lotus root is a typical and delicious food and is widely planted in China. Consequently, abundant lotus leaves are generated every year, but most of them are discarded as waste and rot in water, leading to water pollution. However, the apparent natural features of lotus leaves afford potential advantages for the preparation of hierarchical porous carbon doped with heteroatoms: (1) richness in metal salts or high ash content, which could serve as natural hard templates for the formation of 3D architecture; (2) high contents of protein and lipid, which provide the chance of self-doping with $\mathrm{O}, \mathrm{N}$, and $\mathrm{S}$ heteroatoms. Unfortunately, the production of lotus leavesbased carbon and its application as adsorbent for dye removal remain unexplored.

In this work, 3D hierarchical porous carbon was fabricated from lotus leaves and was applied for the removal of RhB from wastewater. The as-prepared carbon possessed a high surface area of $3601 \mathrm{~m}^{2} / \mathrm{g}$, a good level of O-N-S self-doping, and interconnected multipores with proper pore size distribution. These unique features led to an ultrahigh adsorption capacitance of $9444.39 \mathrm{mg} / \mathrm{g}$ with outstanding cycling stability (>97\% capacitance retention over 10 cycles). The nature of $\mathrm{RhB}$ adsorption onto the resultant carbon was a spontaneous endothermic process and fitted the pseudo-second-order kinetic model and the Langmuir isotherm model the best. The adsorption mechanism of $\mathrm{RhB}$ onto the as-prepared carbon was also investigated. Thus, lotus leaves, as an abundant and renewable biomass, are a significantly promising resource for the production of superadsorbents for the purification of dye-containing wastewater.

\section{RESULTS AND DISCUSSION}

2.1. Material Characterizations. Figure 1 shows the thermogravimetric-mass spectrometry (TG-MS) analysis results of lotus leaves. As shown in Figure 1a, there are several weight loss peaks, which was due to the complex compositions in lotus leaves, including hemicellulose, cellulose, lipid, protein, lignin, and tannin. The small mass loss at the temperature below $200{ }^{\circ} \mathrm{C}$ was attributed to the dehydration of lotus leaves and ended very quickly. It was noteworthy that the major weight loss occurred in the range of $200-600{ }^{\circ} \mathrm{C}$ by giving out volatiles, such as $\mathrm{H}_{2} \mathrm{O}, \mathrm{CO}, \mathrm{CO}_{2}, \mathrm{O}_{2}, \mathrm{H}_{2}$, and $\mathrm{CH}_{4}$ (shown in Figure $1 \mathrm{~b}$ ), resulting from the thermal decomposition of cellulose, hemicelluloses, lipid, protein, and lignin in lotus leaves. Above $600{ }^{\circ} \mathrm{C}$, two slight mass loss peaks were observed, so most of the volatiles were released before the temperature of $600{ }^{\circ} \mathrm{C}$.

The micromorphology of the as-prepared lotus leavesderived hierarchical porous carbon (LLHPC) was first detected by scanning electron microscopy (SEM). As depicted in Figure 2a-c, LLHPC exhibited a 3D porous structure with interconnected pores, which was attributed to $\mathrm{KOH}$ chemical activation process via $\mathrm{C}+6 \mathrm{KOH} \rightarrow 2 \mathrm{~K}_{2} \mathrm{CO}_{3}+2 \mathrm{~K}+3 \mathrm{H}_{2}$, $\mathrm{K}_{2} \mathrm{CO}_{3} \rightarrow \mathrm{K}_{2} \mathrm{O}+\mathrm{CO}_{2}, \mathrm{~K}_{2} \mathrm{CO}_{3}+2 \mathrm{C} \rightarrow 2 \mathrm{~K}+3 \mathrm{CO}$, and $\mathrm{K}_{2} \mathrm{O}+$ $2 \mathrm{C} \rightarrow 2 \mathrm{~K}+\mathrm{CO}$ with the successive post-treatment of $\mathrm{HCl}^{28,29}$ It is noticeable that the abundant interconnected pores and open cavities obviously promoted the rapid diffusion/transfer from liquid to solid and the adsorption of dye molecules onto LLHPC. The X-ray diffraction (XRD) patterns of the as-obtained LLHPC before and after dye adsorption are presented in Figure 3 . The broad and weak reflections located at about 23 and $43^{\circ}$ were assigned to the (002) and (100) planes of the graphite carbon, which were the characteristic signals of the turbostratic carbon structure. ${ }^{30,31}$ Obviously, the ultrastrong intensity in the small-angle region $\left(2 \theta<20^{\circ}\right)$ indicated the presence of a great number of micropores in LLHPC. ${ }^{31}$ Thus, LLHPC is the amorphous carbon material with $3 \mathrm{D}$ porous architecture.

X-ray photoelectron spectroscopy (XPS) was further applied to determine the chemical composition and states of surface atoms of the as-synthesized material, and the results are displayed in Figure 4. The contents of $\mathrm{C}, \mathrm{O}, \mathrm{N}$, and $\mathrm{S}$ in LLHPC were $86.49,10.20,1.44$, and 1.78 at \%, respectively. The $\mathrm{C} 1 \mathrm{~s}$ spectrum was deconvoluted into four peaks of $\mathrm{C}-\mathrm{C}$ $(\sim 284.8 \mathrm{eV}), \mathrm{C}-\mathrm{N}(\sim 285.7 \mathrm{eV}), \mathrm{C}=\mathrm{O}(\sim 287.1 \mathrm{eV})$, and COOR $(\sim 290 \mathrm{eV}) .^{32,33}$ The high-resolution spectrum of O 1s demonstrated three kinds of oxygen-containing functional groups of $\mathrm{C}=\mathrm{O}(\sim 532.2 \mathrm{eV}), \mathrm{C}-\mathrm{O}(\sim 533.2 \mathrm{eV})$, and COOR $(\sim 534 . \mathrm{eV}){ }^{34}$ The $\mathrm{N}$ 1s spectrum was fitted into two peaks at $\sim 399$ and $\sim 402 \mathrm{eV}$, indicating the presence of pyridine and quaternary. ${ }^{35}$ The $S 2 \mathrm{p}$ spectrum revealed the existence of sulfone bridges $\left(\mathrm{C}-\mathrm{SO}_{x}-\mathrm{C}\right)$ centered at $\sim 169.0$ and $\sim 170.2$ $\mathrm{eV}^{24}$ These results demonstrated the successful self-doping of $\mathrm{O}, \mathrm{N}$, and $\mathrm{S}$ heteroatoms in the as-prepared carbon material. It was known that the doping of $\mathrm{O}, \mathrm{N}$, and $\mathrm{S}$ heteroatoms and the 

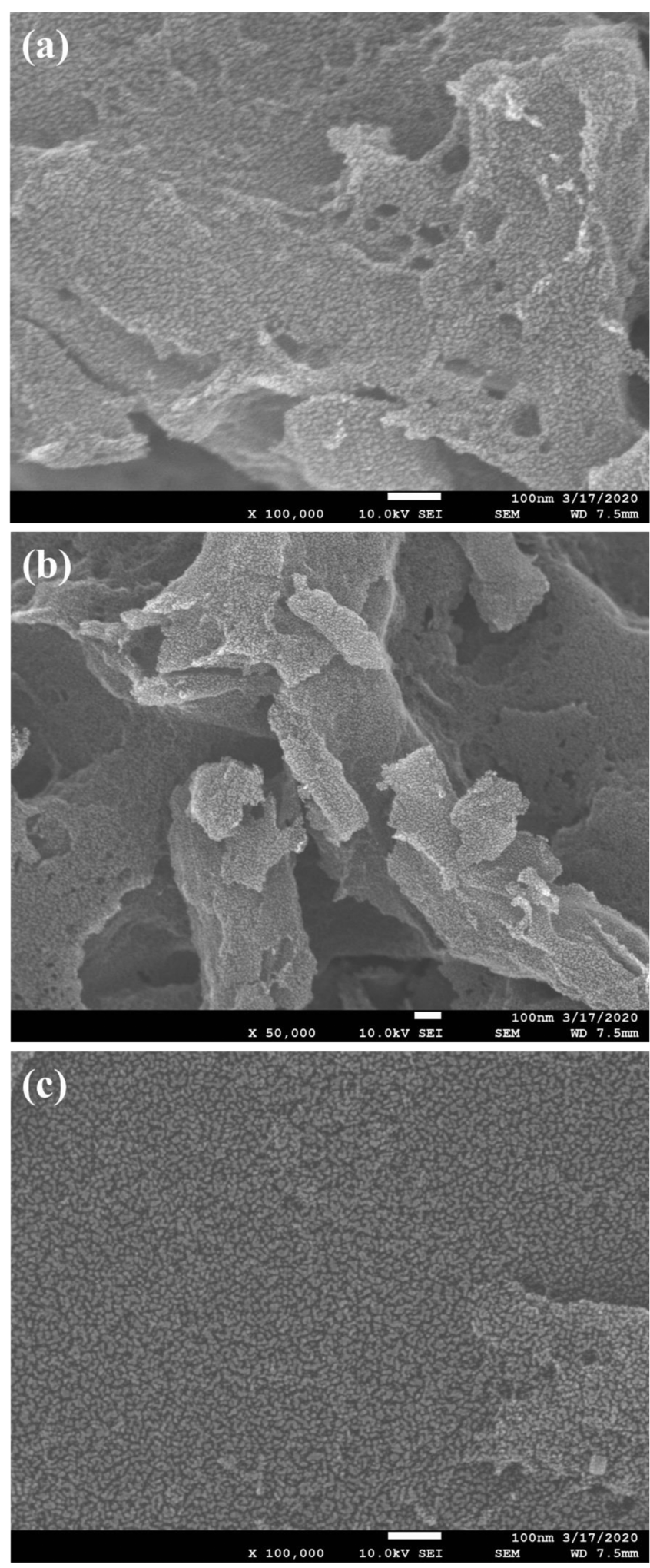

Figure 2. SEM images of as-prepared LLHPC $(a-c)$.

related polar groups not only enhanced the hydrogen bond/ acid-base interaction between the adsorbent and dye molecules but also improved the wettability, thereby increasing the pore accessibility and accelerating the diffusion of adsorbate molecules.

The specific surface area and pore property of the asobtained LLHPC were measured by $\mathrm{N}_{2}$ adsorption and

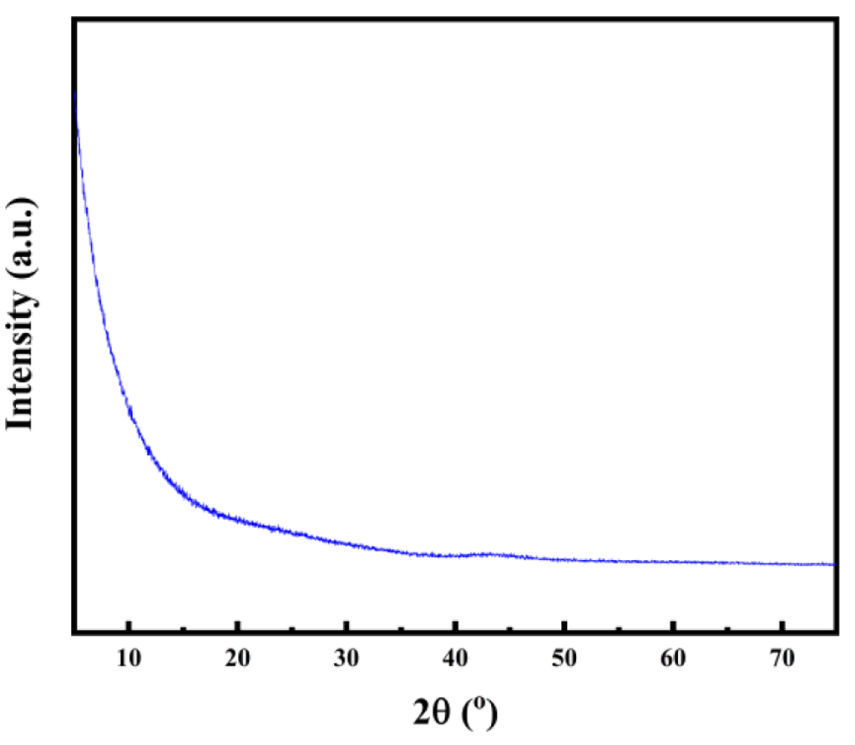

Figure 3. XRD pattern of as-synthesized LLHPC.

desorption analyses at $-196{ }^{\circ} \mathrm{C}$. Figure 5a,b depicts the $\mathrm{N}_{2}$ adsorption-desorption isotherm and pore size distribution. It can be seen from Figure 5a that LLHPC possessed an ultrahigh adsorption capacitance and showed the combined characteristics of type I and IV isotherms with a hysteresis loop. The dramatic increase in the volume adsorbed at a relative pressure $<0.05$ indicated the existence of a great number of micropores, in agreement with the analyses of SEM and XRD. The observation of the hysteresis loop resulting from the high capillary effect at a relative pressure in the range of $0.4-0.8$ suggested the presence of a mesopore structure. Moreover, the slight increase at a relative pressure $>0.8$ demonstrated the presence of a number of macropores. Additionally, the pore size distribution in Figure $5 \mathrm{~b}$ also revealed the microporous and mesoporous structures with the presence of macropores. Thus, the hierarchical porous carbon material was successfully synthesized, which benefited the fast adsorption and diffusion/ transportation of adsorbate molecules. ${ }^{13,16}$ Consequently, LLHPC was confirmed to possess a high surface area of $3601 \mathrm{~m}^{2} / \mathrm{g}$, a large pore volume of $2.44 \mathrm{~cm}^{3} / \mathrm{g}$ (micropore volume of $0.93 \mathrm{~cm}^{3} / \mathrm{g}$ ), and an average pore diameter of 2.56 $\mathrm{nm}$. Overall, LLHPC had a high surface area, appropriate O$\mathrm{N}-\mathrm{S}$ heteroatom doping, and $3 \mathrm{D}$ architecture with multiconnected micro/meso/macropores with proper pore size distribution. These admirable properties may make the asprepared carbon material a significant superadsorbent for the efficient removal of dye from wastewater.

2.2. Dye Adsorption Capability. The influences of adsorption parameters (e.g., contact time, $\mathrm{pH}$, initial concentration, and temperature) were studied at the beginning, and the results are shown in Figure 6. The impact of contact time on the adsorption capacitance is depicted in Figure $6 \mathrm{a}, \mathrm{b}$, which was carried out by the mixture of $10 \mathrm{mg}$ of LLHPC and $100 \mathrm{~mL}$ of $\mathrm{RhB}$ solution $(200 \mathrm{mg} / \mathrm{L})$ at room temperature and $\mathrm{pH}$ value of $7 . q_{t}$ drastically increased in the first $10 \mathrm{~min}$ and then reached equilibrium with $q_{\mathrm{e}}$ of 1990.7 $\mathrm{mg} / \mathrm{g}$ and the dye removal percentage of $99.5 \%$, suggesting the fast and efficient purification of RhB-containing wastewater. It was attributed to the $3 \mathrm{D}$ interconnected hierarchical porous structure with suitable pore size distribution boosting the diffusion of dye molecules, high surface area, and good level of 

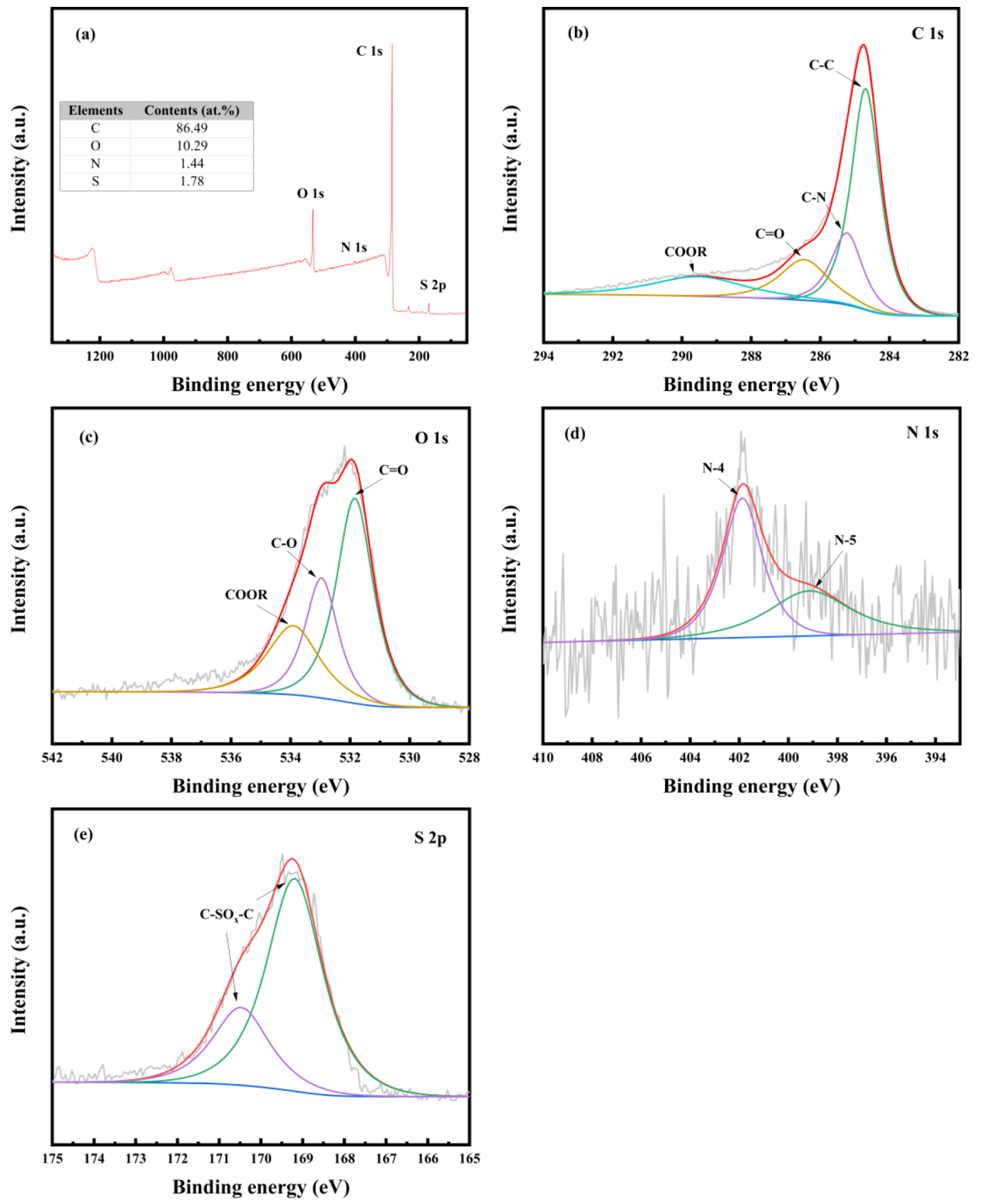

Figure 4. (a) Full XPS spectrum, (b) C 1s spectrum, (c) O 1s spectrum, (d) N 1s spectrum, and (e) S 2p spectrum of as-prepared LLHPC.

$\mathrm{O}-\mathrm{N}-\mathrm{S}$ heteroatom doping, offering immense active sites for $\mathrm{RhB}$ adsorption. The relation between the adsorption capability and the initial $\mathrm{pH}$ value is displayed in Figure 6c, performed by immersing $10 \mathrm{mg}$ of LLHPC in $100 \mathrm{~mL}$ of 200 $\mathrm{mg} / \mathrm{L} \mathrm{RhB}$ solution at room temperature and $\mathrm{pH}$ value in the range of 3-11. The increase in $\mathrm{pH}$ value showed a favorable impact on the enhancement of adsorption rate; the rise in $\mathrm{pH}$ increased the negative charge of LLHPC and enhanced the electrostatic interaction between LLHPC and $\mathrm{RhB}$ molecules (cationic dye). ${ }^{4,17}$ Noticeably, the change of $\mathrm{pH}$ just led to a small change of the adsorption rate and prolonged the time to adsorption equilibrium but showed no effect on the adsorption capacitances at equilibrium, indicating significant potential of the adsorbent toward $\mathrm{RhB}$ in a wide $\mathrm{pH}$ range. The effects of initial concentration and temperature are illustrated in Figure 6d, which were examined at different temperatures (25-60 ${ }^{\circ} \mathrm{C}$ ) and a $\mathrm{pH}$ value of 7 by using $10 \mathrm{mg}$ of adsorbent and 100 $\mathrm{mL}$ of $\mathrm{RhB}$ solution with different initial concentrations (200, 400 , and $600 \mathrm{mg} / \mathrm{L}$ ). It was found that both the initial concentration and the temperature showed beneficial impacts on the adsorption capacity. Two reasons accounted for the results. First, the growth in initial concentration enhanced the driving force to overcome the mass transfer resistance of the adsorbate between the liquid and the solid adsorbent. ${ }^{36}$ Second, the adsorption of RhB onto LLHPC was an endothermic process.

For the adsorption kinetic assessment, the fitting linear plots of $\mathrm{RhB}$ adsorption performance of LLHPC as a function of contact time are displayed in Figure 7 and the linked parameters are listed in Table 1. It was found that the 

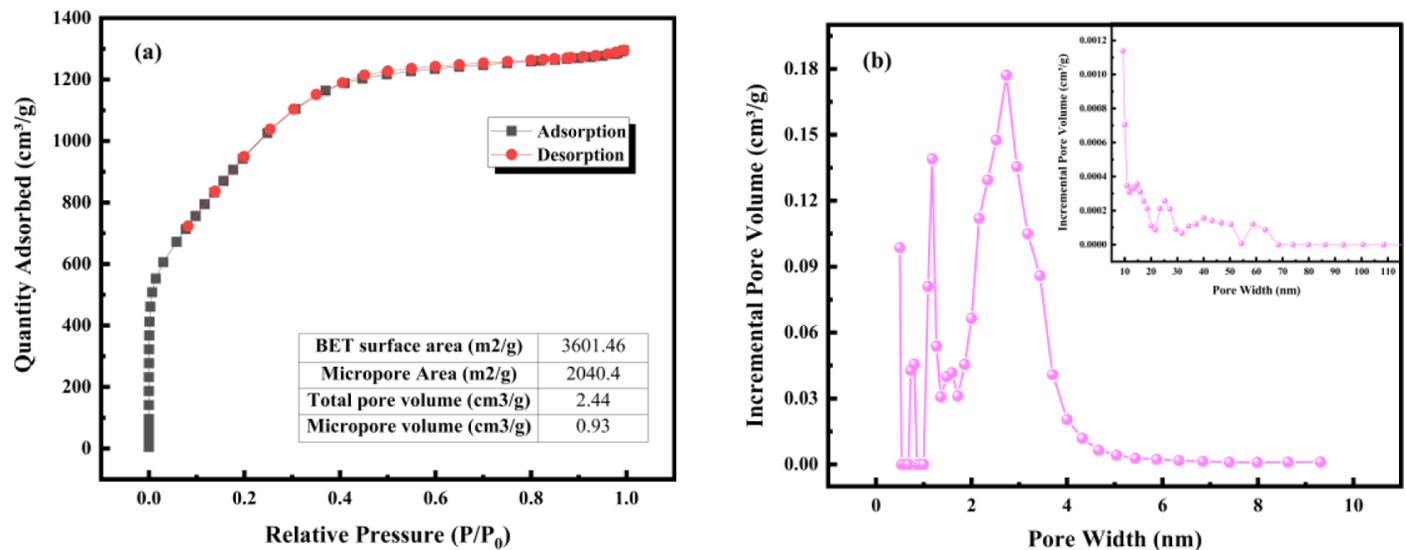

Figure 5. (a) $\mathrm{N}_{2}$ adsorption-desorption isotherm and (b) pore size distribution of as-obtained LLHPC.
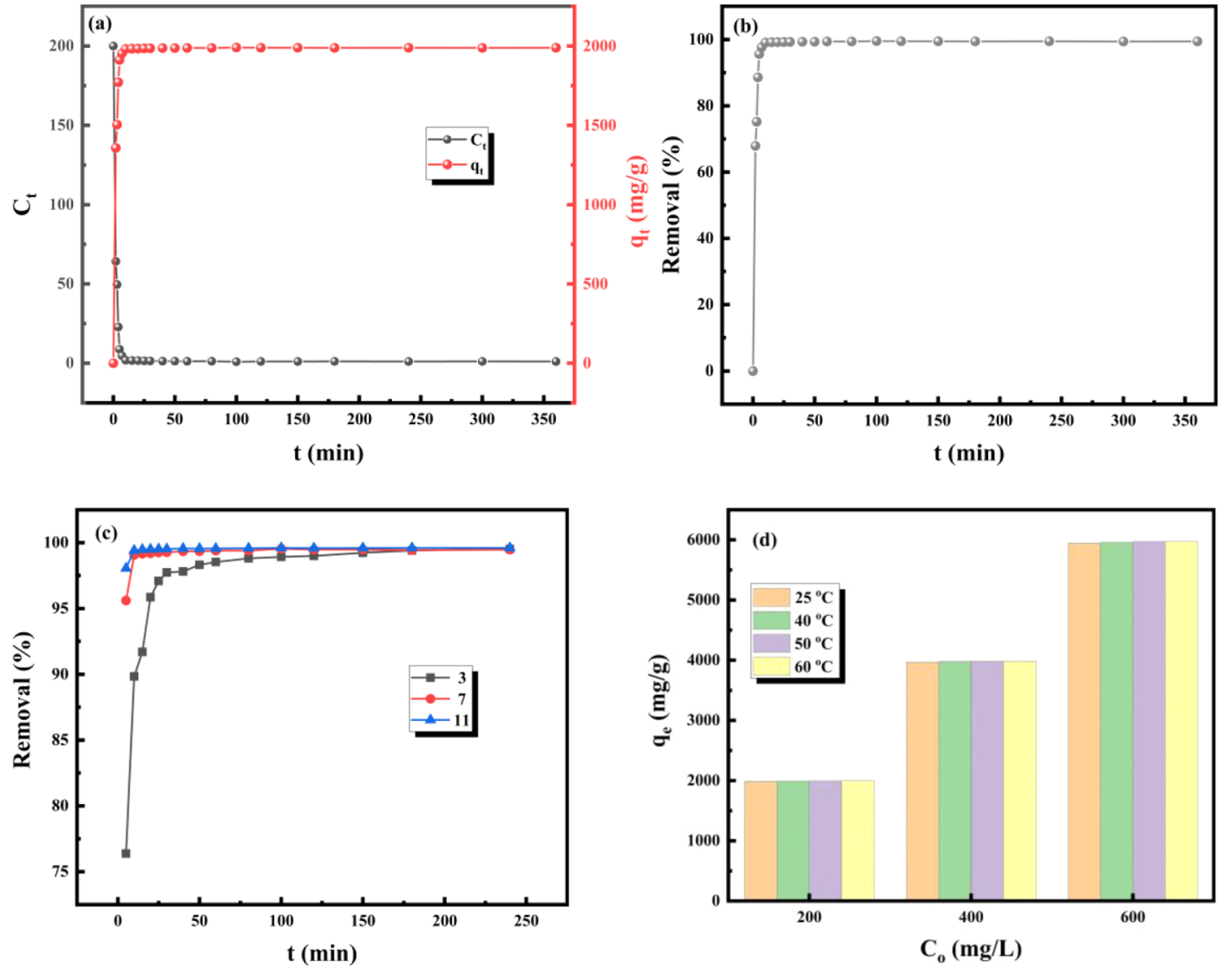

Figure 6. Effects of $(\mathrm{a}, \mathrm{b})$ contact time, $(\mathrm{c})$ initial $\mathrm{pH}$, and $(\mathrm{d})$ initial concentration and adsorption temperature on the adsorption performance of as-prepared LLHPC.

pseudo-second-order kinetic model described best the adsorption of $\mathrm{RhB}$ onto as-prepared carbon with the highest $R^{2}$ value of 1.0 , and the calculated adsorption capacitance $\left(q_{\mathrm{e}}\right)$ of $1991.13 \mathrm{mg} / \mathrm{g}$ was very close to the experimental value. Therefore, the adsorption of RhB onto LLHPC allowed the pseudo-second-order kinetic model, indicating the natural adsorption process of chemisorption. It was attributed to $\mathrm{O}-$ $\mathrm{N}-\mathrm{S}$ heteroatom doping and the related functional groups.

For the adsorption isotherm evaluation, the fitting linear plots of experimental data as a function of equilibrium concentration are displayed in Figure 8 and the associated parameters are summarized in Table 2. It can be seen that the adsorption process of $\mathrm{RhB}$ onto LLHPC followed the
Langmuir isotherm model best with the highest $R^{2}$ of 0.9925, revealing the uniformity of the adsorption sites over LLHPC and the monolayer adsorption of RhB molecules with no transmigration. The maximum monolayer adsorption capacity $\left(Q_{\max }\right)$, determined by the application of the Langmuir isotherm model was a new record of $9444.39 \mathrm{mg} /$ g, highest among those reported in the literature, ${ }^{13,18,37}$ which resulted from the high surface area, hierarchical porous structure, and $\mathrm{O}-\mathrm{N}-\mathrm{S}$ codoping. Equilibrium parameter $\left(R_{\mathrm{L}}\right)$ was calculated from $R_{\mathrm{L}}=\frac{1}{1+K_{\mathrm{L}} C_{\mathrm{o}}}$ to investigate the feasibility of adsorption onto the adsorbent, and $R_{\mathrm{L}}$ (0.004- 

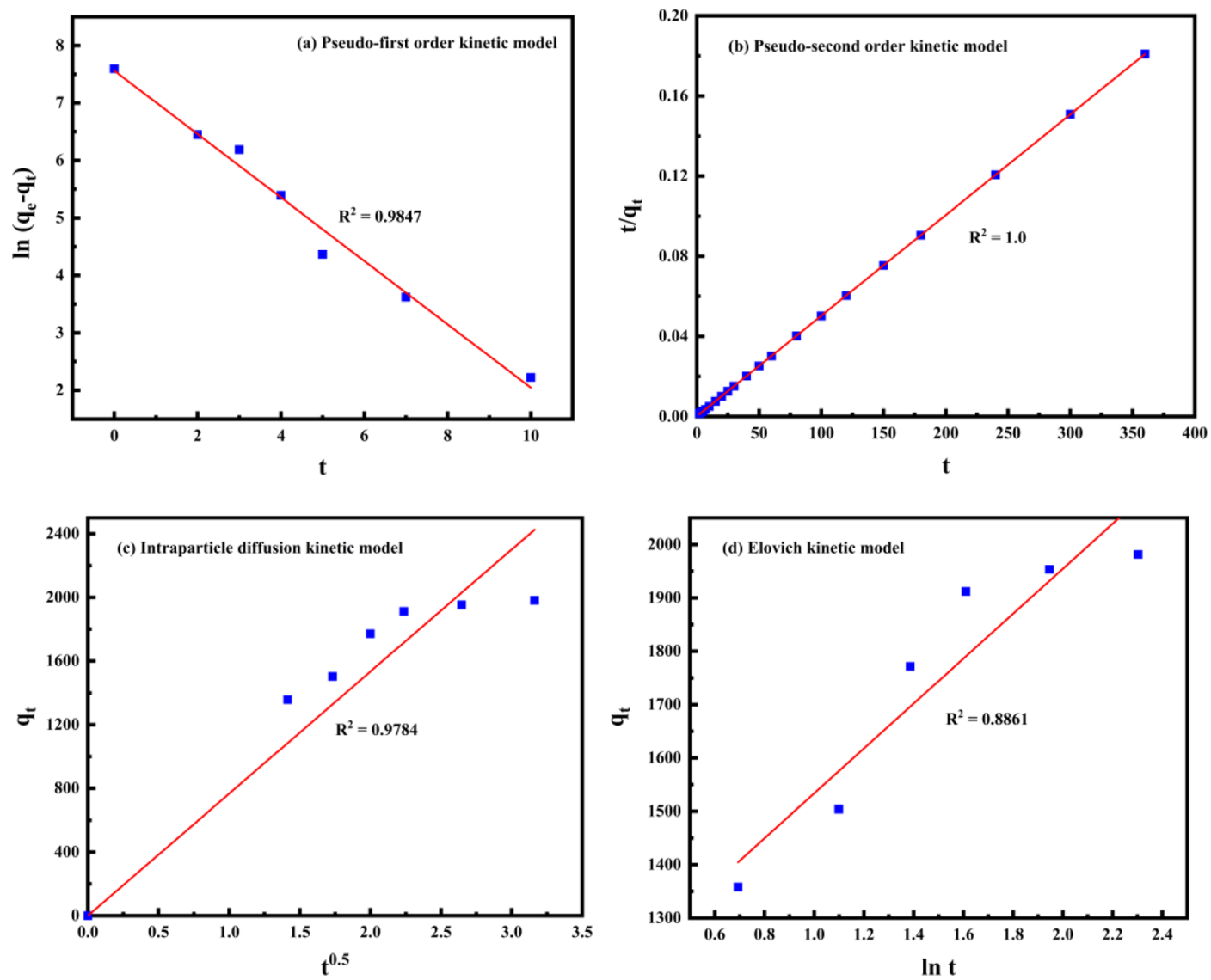

Figure 7. Linear plots of (a) $\ln \left(q_{\mathrm{e}}-q_{t}\right)$ as a function of $t$, (b) $t / q_{t}$ as a function of $t$, (c) $q_{t}$ as a function of $t^{0.5}$, and (d) $q_{t}$ as a function of $t \ln t$ for the dye adsorption process onto LLHPC.

Table 1. $R^{2}$ and Constant Values for the Different Adsorption Kinetics Models

\begin{tabular}{|c|c|}
\hline models & pseudo-first-order \\
\hline$R^{2}$ & 0.9847 \\
\hline constants & $0.5519 \mathrm{~min}^{-1}$ \\
\hline
\end{tabular}

0.018 ) was in the range of $0-1$, indicating the favorable nature of adsorption process onto LLHPC. ${ }^{38,39}$

For the adsorption thermodynamic study, the linear plots of $\ln K_{\mathrm{c}}$ against $1 / T$ are shown in Figure 9 and the associated parameters, calculated from the linear regression analysis, are summarized in Table 3. The positive values of $\Delta H^{\circ}$ and $\Delta S^{\circ}$ indicated the endothermic nature of the adsorption process and the increase of system randomness, whereas the negative value of $\Delta G^{\circ}$ demonstrated the spontaneous nature of $\mathrm{RhB}$ adsorbed onto LLHPC. As a result, the porous carbon derived from lotus leaves exhibited ultraexcellent adsorption rate and adsorption capacitance. Hence, it is an efficient and low-cost alternative superadsorbent for wastewater treatment, especially for dye removal.

The reusability stabilization is an important factor for the practical application of LLHPC in the purification of wastewater. It can be seen from Figure 10 that the adsorption capacity of LLHPC slightly decreased from 7798.9 to 7609.9 $\mathrm{mg} / \mathrm{g}$ after four cycles and then remained stable at $\sim 7600 \mathrm{mg} /$ $\mathrm{g}$ with the capacitance retention of $>97 \%$. Consequently, the as-synthesized LLHPC exhibited outstanding recyclability for the purification of dye-containing wastewater.

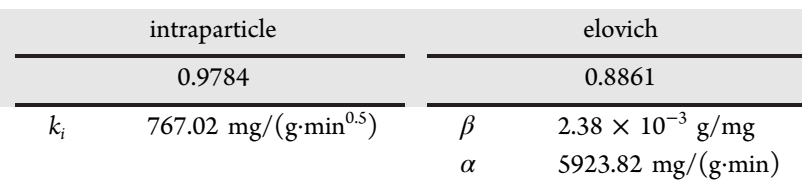

The Fourier transform infrared (FTIR) spectrum was applied to comprehend the adsorption mechanism of $\mathrm{RhB}$ molecules onto LLHPC. Figure 11 displays the FTIR spectra of pure RhB and LLHPC before and after the adsorption of dye molecules. The FTIR spectrum of unused LLHPC powder offered the characteristics of organic groups below: the signal at $\sim 3430 \mathrm{~cm}^{-1}$ belonged to the stretching vibration of $\mathrm{O}-\mathrm{H}$ or $\mathrm{N}-\mathrm{H}^{40}$ the peak at $\sim 2930 \mathrm{~cm}^{-1}$ was attributed to the $\mathrm{C}-\mathrm{H}$ stretching vibration of methyl groups; ${ }^{41}$ the band at $1628 \mathrm{~cm}^{-1}$ corresponded to the stretching vibrations of $\mathrm{C}=\mathrm{O}, \mathrm{C}=\mathrm{C}$, and $\mathrm{C}=\mathrm{N}$; ${ }^{42}$ the narrow band at $\sim 1400 \mathrm{~cm}^{-1}$ was assigned to the $\mathrm{C}-\mathrm{N}$ stretching vibration; ${ }^{40}$ the adsorptions from 1330 to 940 $\mathrm{cm}^{-1}$ were identified as the response of $\mathrm{C}-\mathrm{N}, \mathrm{C}-\mathrm{O}$, and $\mathrm{S}=\mathrm{O}$ stretching vibrations; and the peak at $1048 \mathrm{~cm}^{-1}$ was attributed to the $\mathrm{C}-\mathrm{O}-\mathrm{C}$ stretching vibration. These results are consistent with those of the XPS analyses. The FTIR spectrum of spent LLHPC displayed the apparent combined adsorption information of LLHPC and RhB, demonstrating the successful adsorption of $\mathrm{RhB}$ onto LLHPC. It was evident that the surface of as-prepared LLHPC located abundant oxygenfunctional groups (e.g., $\mathrm{O}-\mathrm{H}, \mathrm{C}=\mathrm{O}$, and $\mathrm{C}-\mathrm{O}$ ) and $\pi-\pi$ structures, and the structure of the $\mathrm{RhB}$ molecule exhibited a 

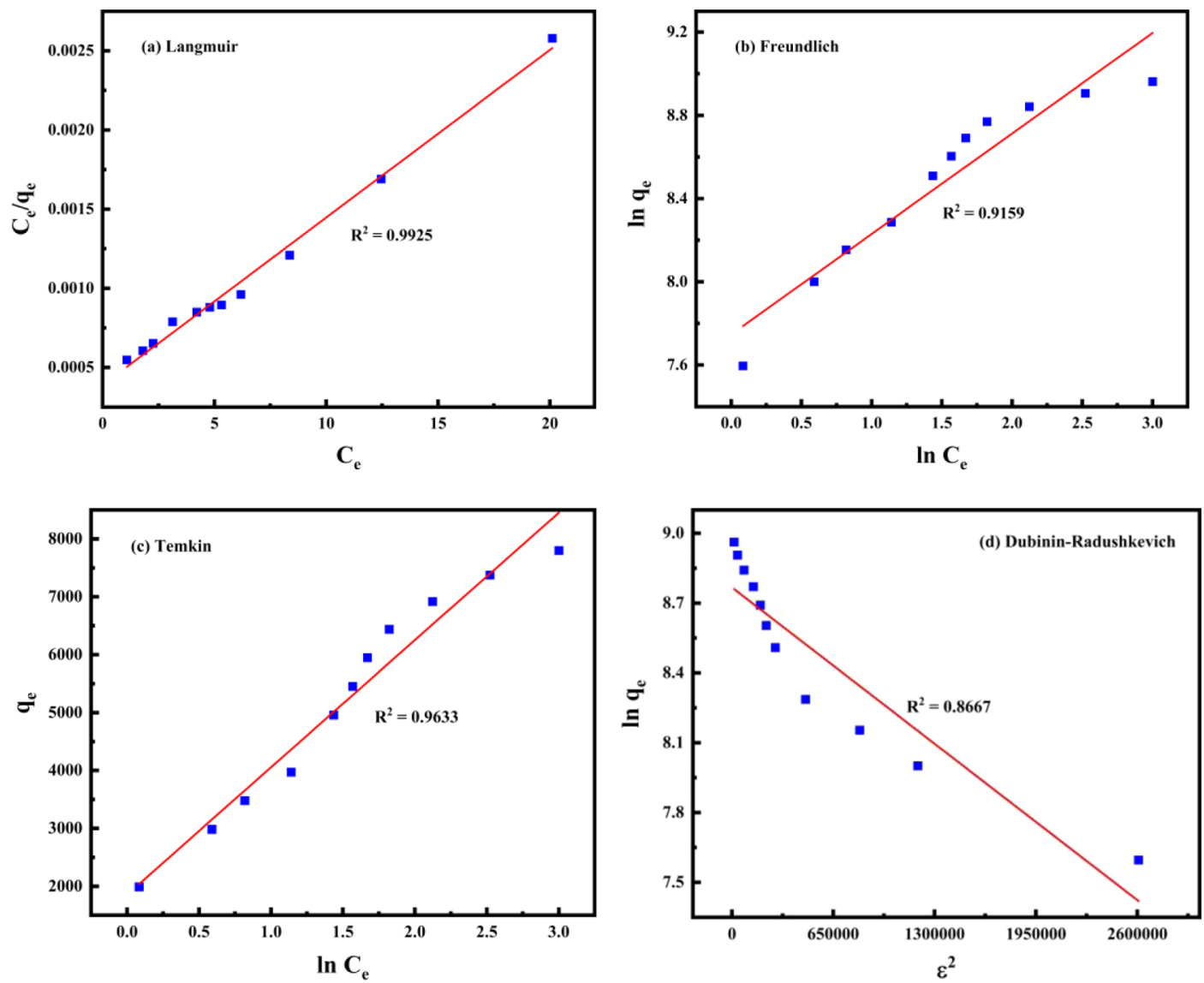

Figure 8. Linear plots of (a) Langmuir isotherm model, (b) Freundlich isotherm model, (c) Temkin isotherm model, and (d) DubininRadushkevich isotherm model for the adsorption of dye onto LLHPC.

\section{Table 2. $R^{2}$ and Constant Values for the Different Isotherm Models}

\begin{tabular}{|c|c|c|c|c|c|c|c|c|}
\hline models & & gmuir & & ndlich & & emkin & \multicolumn{2}{|c|}{ Dubinin-Radushkevich } \\
\hline$R^{2}$ & \multicolumn{2}{|c|}{0.9925} & \multicolumn{2}{|c|}{0.9159} & \multicolumn{2}{|c|}{0.9633} & & 0.8667 \\
\hline constants & $Q_{\max }$ & $9444.39 \mathrm{mg} / \mathrm{g}$ & $1 / n$ & 0.4828 & $\underline{b}_{\mathrm{t}}$ & $1.1271 \mathrm{~J} / \mathrm{mol}$ & $B$ & $5.17 \times 10^{-7} \mathrm{~mol}^{2} \cdot \mathrm{J}^{2}$ \\
\hline & $K_{\mathrm{L}}$ & $0.2727 \mathrm{~L} / \mathrm{g}$ & $K_{\mathrm{F}}$ & $2314.39 \mathrm{~L} / \mathrm{g}$ & $a_{\mathrm{t}}$ & $2.3265 \mathrm{~L} / \mathrm{g}$ & $Q_{m}$ & $6420.62 \mathrm{mg} / \mathrm{g}$ \\
\hline
\end{tabular}

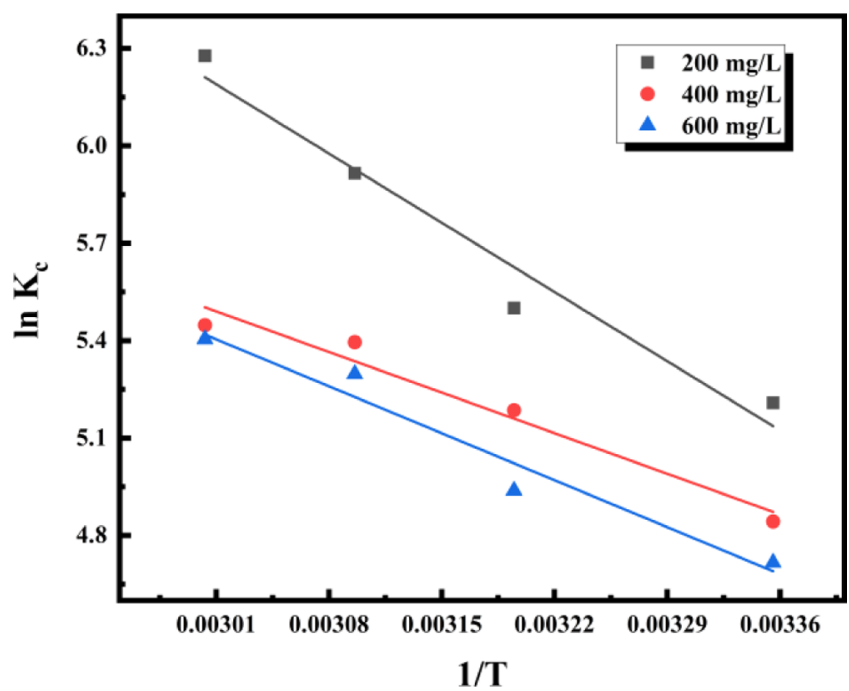

Figure 9. Plots of $\ln K_{\mathrm{c}}$ against $1 / \mathrm{T}$ for the adsorption of $\mathrm{RhB}$ onto LLHPC. hydroxyl group and an aromatic backbone. As a result, the combination of the adsorbate and the adsorbent was concluded to occur via $\pi-\pi$ stacking and the formation of hydrogen bond. In addition, LLHPC was doped with proper level of $\mathrm{O}, \mathrm{N}$, and $\mathrm{S}$ heteroatoms, which can act as the base to provide electrons or accept protons, ${ }^{43}$ and the organic ammonium cations in the RhB molecule can serve as acid to accept electrons or provide protons. Thus, the acid-base interaction also made a contribution to the adsorption of $\mathrm{RhB}$ onto LLHPC. The ultraexcellent adsorption performance resulted from $\pi-\pi$ stacking, hydrogen bond, and acid-base interactions.

\section{CONCLUSIONS}

3D hierarchical porous carbon was successfully derived from lotus leaves and possessed a significantly high surface area of $3601 \mathrm{~m}^{2} / \mathrm{g}$, appropriate $\mathrm{O}-\mathrm{N}-\mathrm{S}$ self-doping, and 3D architecture with interconnected micro/meso/macropores. These advantageous features afforded ultraexcellent adsorption capacity as high as $9444.39 \mathrm{mg} / \mathrm{g}$. The adsorption of dye onto LLHPC was a spontaneous endothermic process and fitted the pseudo-second-order kinetic model and Langmuir isotherm 
Table 3. Thermodynamic Parameters for the Adsorption of RhB Onto Lotus Leaves-Derived Carbon

\begin{tabular}{|c|c|c|c|c|c|c|}
\hline \multirow[b]{2}{*}{ initial concentration $(\mathrm{mg} / \mathrm{L})$} & \multirow[b]{2}{*}{$\Delta H^{\circ}\left(\mathrm{kJ} \cdot \mathrm{mol}^{-1}\right)$} & \multirow[b]{2}{*}{$\Delta S^{\circ}\left(\mathrm{J} \cdot \mathrm{mol}^{-1} \cdot \mathrm{K}^{-1}\right)$} & \multicolumn{4}{|c|}{$\Delta G^{\circ}\left(\mathrm{kJ} \cdot \mathrm{mol}^{-1}\right)$} \\
\hline & & & $298 \mathrm{~K}$ & $313 \mathrm{~K}$ & $323 \mathrm{~K}$ & $333 \mathrm{~K}$ \\
\hline 200 & 25.32 & 127.67 & -12.73 & -14.64 & -15.92 & -17.19 \\
\hline 400 & 14.85 & 90.35 & -12.07 & -13.43 & -14.33 & -15.23 \\
\hline 600 & 17.18 & 96.63 & -11.62 & -13.07 & -14.04 & -15 \\
\hline
\end{tabular}

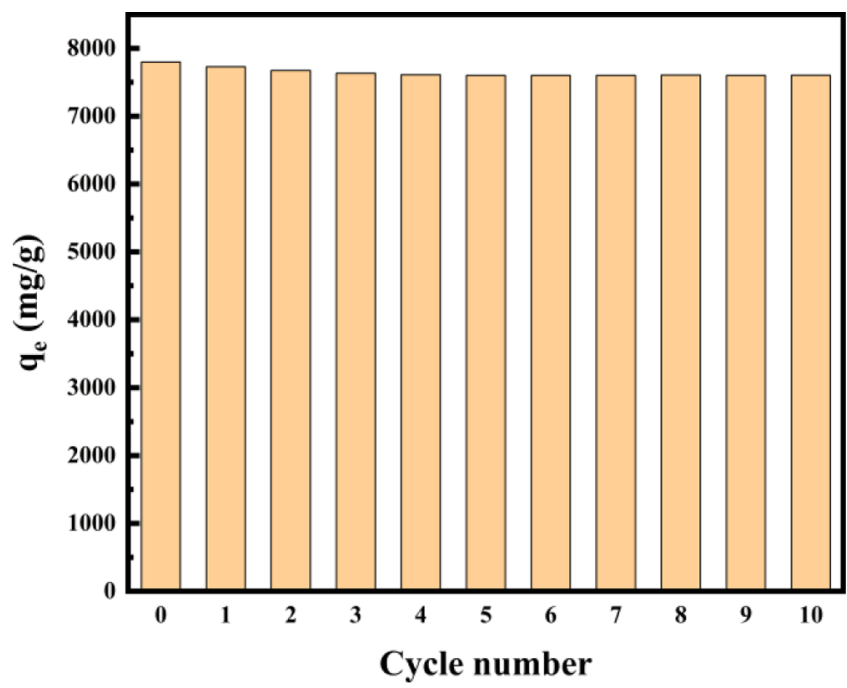

Figure 10. Recycling of LLHPC for adsorption of $\mathrm{RhB}$ by adsorption-desorption processes.

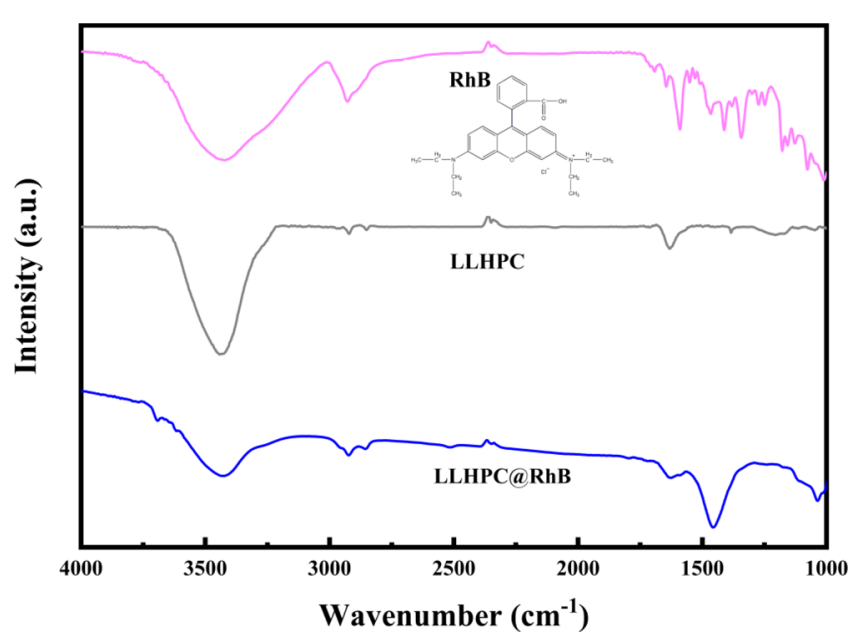

Figure 11. FTIR spectra of pure RhB and LLHPC before and after the adsorption of dye molecules.

model. The adsorption mechanism was mainly attributed to the $\pi-\pi$ stacking, hydrogen bond, and acid-base interactions. The superior adsorption performance closely originated from the natural properties of lotus leaves, including high contents of proteins and lipid for the self-doping of different heteroatoms and richness of metal salts, serving as natural templates for the generation of $3 \mathrm{D}$ architecture. The utilization of lotus leaves as a renewable precursor would pave the way for cost-efficient production of heteroatoms self-doped 3D hierarchical porous carbon.

\section{EXPERIMENTAL SECTION}

4.1. Materials. Lotus leaves were collected from the campus of Anhui Polytechnic University in Wuhu (Anhui province, China). They were first washed with distilled water to remove dust particles and then dried at $110{ }^{\circ} \mathrm{C}$, crushed, and sieved to obtain a uniform grain size in the range of $0.2-$ $0.5 \mathrm{~mm}$. The proximate [according to the Chinese standard (GB/T 28731-2012)] and ultimate analyses of the raw material asre illustrated in Table 4. The ash and nitrogen contents of lotus leaves were 13.63 and $3.15 \%$, which was due to the composition rich in metal salts and protein. Table 5 lists the ash composition; the major components in ash were metallic oxides, such as $\mathrm{CaO}$ and $\mathrm{K}_{2} \mathrm{O}$, which can function as hard templates to generate a porous structure.

4.2. Preparation of Porous LLHPC. Lotus leaves were first pyrolyzed in a fixed bed reactor under $\mathrm{N}_{2}$ protection. The temperature was continuously increased to $600{ }^{\circ} \mathrm{C}$ at a heating rate of $3{ }^{\circ} \mathrm{C} / \mathrm{min}$ and then kept for $1 \mathrm{~h}$. For the activation process, the resultant powder from the previous pyrolysis process was ground with $\mathrm{KOH}$ at the mass ratio of 1: 4 . Subsequently, the mixed powder was placed in a tube furnace and heated to $800{ }^{\circ} \mathrm{C}$ at a rate of $2{ }^{\circ} \mathrm{C} / \mathrm{min}$ and maintained for $1 \mathrm{~h}$ under a $\mathrm{N}_{2}$ atmosphere. Finally, the as-synthesized powder was cooled to room temperature and washed with $1 \mathrm{M} \mathrm{HCl}$ solution and distilled water until neutral and dried at $110{ }^{\circ} \mathrm{C}$ overnight to obtain LLHPC.

4.3. Characterizations. The elemental analyses in the lotus leaves were performed by an elemental analyzer (Elementar, vario MACRO CHN). An X-ray fluorescence (XRF) analyzer (Panalytical, AXIOS) was used to analyze the compositions of the ash derived from lotus leaves. The thermal behavior of lotus leaves was evaluated with a thermal analyzer (Hitachi, TG/DTA 7300). The samples were heated up to 900 ${ }^{\circ} \mathrm{C}$ in an $\mathrm{Ar}$ atmosphere at a heating rate of $5{ }^{\circ} \mathrm{C} / \mathrm{min}$. Brunauer-Emmett-Teller (BET) surface area, pore volume, and pore size of the activated carbons were analyzed by $\mathrm{N}_{2}$ adsorption/desorption measurements (Micrometric, model ASAP2020). The sample was first degassed at $250{ }^{\circ} \mathrm{C}$ under vacuum overnight, and then the analysis was carried out by using $\mathrm{N}_{2}$ as an adsorbate gas at $-196{ }^{\circ} \mathrm{C}$. BET surface area and pore size distribution were determined by the BET theory and the nonlocal density functional theory, respectively.

4.4. Adsorption Test. For the dye adsorption test onto assynthesized LLHPC, batch adsorption experiments were

Table 4. Proximate and Ultimate Analyses of Lotus Leaves

\begin{tabular}{|c|c|c|c|c|c|c|c|c|}
\hline \multicolumn{4}{|c|}{ proximate analysis (wt \%) } & \multicolumn{5}{|c|}{ ultimate analysis (wt \%) } \\
\hline moisture & ash & volatile & fixed carbon & $\mathrm{C}$ & $\mathrm{H}$ & $\mathrm{O}$ & $\mathrm{N}$ & $S$ \\
\hline 5.08 & 13.63 & 64.62 & 16.67 & 43.59 & 5.49 & 47.19 & 3.15 & 0.58 \\
\hline
\end{tabular}


Table 5. Results of XRF Analyses of the Ash from Lotus Leaves (wt \%)

\begin{tabular}{ccccccccccccccccc}
$\mathrm{CaO}$ & $\mathrm{K}_{2} \mathrm{O}$ & $\mathrm{P}_{2} \mathrm{O}_{5}$ & $\mathrm{Cl}$ & $\mathrm{MgO}$ & $\mathrm{SO}_{3}$ & $\mathrm{MnO}$ & $\mathrm{SiO}_{2}$ & $\mathrm{Na}_{2} \mathrm{O}$ & $\mathrm{Fe}_{2} \mathrm{O}_{3}$ & $\mathrm{SrO}_{2}$ & $\mathrm{Al}_{2} \mathrm{O}_{3}$ & $\mathrm{Rb}_{2} \mathrm{O}$ & $\mathrm{ZnO}_{2}$ \\
\hline 55.611 & 18.691 & 8.312 & 6.994 & 3.993 & 2.975 & 1.845 & 0.592 & 0.443 & 0.216 & 0.147 & 0.066 & 0.056 & 0.040
\end{tabular}

performed by mixing a given amount of LLHPC and RhB aqueous solution at a preset $\mathrm{pH}$ value and successively shaking for a certain period of time. After centrifugation for about 15 min to remove LLHPC powder, the $\mathrm{RhB}$ concentration remaining in the solution was measured by an ultravioletvisible spectrophotometer (Shimadzu, UV 2700) at the wavelength of $554 \mathrm{~nm}$. The impacts of contact time, $\mathrm{pH}$ value, initial $\mathrm{RhB}$ concentration, and adsorption temperature were explored.

The amount of adsorbed dye $\left(q_{t}\right)$ onto LLHPC and dye removal percentage (removal) were determined from eqs 1 and 2 , respectively. ${ }^{13,36}$

$$
\begin{aligned}
& q_{t}=\frac{\left(C_{\mathrm{o}}-C_{t}\right) \times V}{m} \\
& \text { removal }=\frac{C_{\mathrm{o}}-C_{t}}{C_{\mathrm{o}}} \times 100 \%
\end{aligned}
$$

where $q_{t}(\mathrm{mg} / \mathrm{g})$ is the dye adsorption capacitance onto LLHPC at $t(\mathrm{~min}), C_{\mathrm{o}}(\mathrm{mg} / \mathrm{L})$ is the initial $\mathrm{RhB}$ concentration, $C_{t}(\mathrm{mg} / \mathrm{L})$ is the $\mathrm{RhB}$ concentration remaining in the solution at $t(\mathrm{~min}), V(\mathrm{~L})$ is the volume of RhB solution, and $m(\mathrm{~g})$ is the mass weight of LLHPC used in experiment.

The adsorption experiments for the adsorption kinetic assessment were carried out at room temperature by immersing $10 \mathrm{mg}$ of LLHPC powder in $100 \mathrm{~mL}$ of $200 \mathrm{mg} /$ $\mathrm{L} \mathrm{RhB}$ solution at a $\mathrm{pH}$ value of 7 . The concentration of the remaining dye was measured at certain time intervals. The four kinetic models of pseudo-first-order, pseudo-second-order, intraparticle diffusion, and elovich were used to describe the relation between adsorption performance and contact time. The linear equations and the linked parameters of these kinetic models are summarized in Table $6 .^{36}$

To disclose the interaction between the adsorbate and the adsorbent, the adsorption isotherm study was performed at room temperature by mixing $10 \mathrm{mg}$ of LLHPC with $100 \mathrm{~mL}$ of $\mathrm{RhB}$ solution in the range of $100-800 \mathrm{mg} / \mathrm{L}$ at $\mathrm{pH}$ 7. The mixture was shaken for $12 \mathrm{~h}$ until the adsorption equilibrium reached. The four kinds of isotherm models, namely, Langmuir, Freundlich, Temkin, and Dubinin-Radushkevich, were applied to fit the adsorption performance of $\mathrm{RhB}$ onto LLHPC against equilibrium concentration, and the linear equations and the associated parameters are listed in Table 6 as well. $^{36}$

To comprehend the nature and feasibility of RhB adsorption onto as-obtained carbon, adsorption thermodynamic evaluation was undertaken in the temperature range of $25-60{ }^{\circ} \mathrm{C}$ with different initial concentrations of $100 \mathrm{~mL}$ of $\mathrm{RhB}$ solution (200-600 mg/L) by using $10 \mathrm{mg}$ of LLHPC; $\mathrm{pH}$ and contact time were controlled at 7 and $12 \mathrm{~h}$, respectively. Thermodynamic parameters were calculated from the following equations. $^{11,17}$

$$
\begin{aligned}
& \Delta G^{\circ}=-R T \ln K_{\mathrm{c}} \\
& K_{\mathrm{c}}=\frac{C_{\mathrm{o}}-C_{\mathrm{s}}}{C_{\mathrm{s}}}
\end{aligned}
$$

Table 6. Equations and Parameters of Kinetic and Isotherm Models $^{a}$

\begin{tabular}{lll} 
models & \multicolumn{1}{c}{ names } & \multicolumn{1}{c}{ expressions } \\
kinetic & pseudo-first-order & $\ln \left(q_{\mathrm{e}}-q_{\mathrm{t}}\right)=\ln q_{\mathrm{e}}-k_{\mathrm{t}} t$ \\
& pseudo-second-order & $\frac{t}{q_{t}}=\frac{t}{q_{e}}+\frac{1}{k_{2} q_{\mathrm{e}}^{2}}$ \\
& intraparticle diffusion & $q_{t}=k_{\mathrm{i}} t^{0.5}$ \\
& elovich & $q_{t}=\frac{1}{\beta} \ln (\alpha \beta)+\frac{1}{\beta} \ln t$ \\
isotherm & & $\frac{C_{\mathrm{e}}}{q_{\mathrm{e}}}=\frac{1}{K_{\mathrm{L}} Q_{\max }}+\frac{C_{\mathrm{e}}}{Q_{\max }}$ \\
& Langmuir & $R_{\mathrm{L}}=\frac{1}{1+K_{\mathrm{L}} C_{\mathrm{o}}}$ \\
& & $\ln q_{\mathrm{e}}=\ln K_{\mathrm{F}}+1 / n \ln C_{\mathrm{e}}$ \\
& Freundlich & $q_{\mathrm{e}}=\frac{R T}{b_{t}} \ln a_{t}+\frac{R T}{b_{t}} \ln C_{\mathrm{e}}$ \\
& Temkin & $\ln q_{\mathrm{e}}=\ln Q_{\mathrm{m}}-B \varepsilon^{2}$ \\
& Dubinin-Radushkevich & $\varepsilon=R T \ln \left(1+\frac{1}{C_{\mathrm{e}}}\right)$
\end{tabular}

${ }^{a} k_{1}\left(\mathrm{~min}^{-1}\right), k_{2}\left(\mathrm{~g} \cdot \mathrm{mg}^{-1} \cdot \mathrm{min}^{-1}\right)$ and $k_{i}\left(\mathrm{mg} \cdot \mathrm{g}^{-1} \cdot \mathrm{min}^{-0.5}\right)$ represent the rate constants, $\alpha\left(\mathrm{mg} \cdot \mathrm{g}^{-1} \cdot \mathrm{min}^{-1}\right)$ is the initial adsorption rate, and $\beta$ $(\mathrm{g} / \mathrm{mg})$ is the desorption rate. $Q_{\max }(\mathrm{mg} / \mathrm{g})$ is the maximum adsorption capability, $K_{\mathrm{L}}(\mathrm{L} / \mathrm{mg})$ and $K_{\mathrm{F}}(\mathrm{L} / \mathrm{g})$ are the constants, $1 / n$ presents the heterogeneity of the adsorbent surface, $a_{t}(\mathrm{~L} / \mathrm{g})$ and $b_{t}(\mathrm{~J} / \mathrm{mol})$ are the constants of Temkin isotherm, $B$ is a constant, $Q_{m}$ $(\mathrm{mg} / \mathrm{g})$ is the saturation adsorption capacity, and $\varepsilon$ is the Poanyi potential.

$$
\ln K_{\mathrm{c}}=-\frac{\Delta G^{\circ}}{R T}=-\frac{\Delta H^{\circ}}{R T}+\frac{\Delta S^{\circ}}{R}
$$

where $\Delta G^{\circ}(\mathrm{J} / \mathrm{mol}), \Delta H^{\circ}(\mathrm{J} / \mathrm{mol})$, and $\Delta S^{\circ}\left(\mathrm{J} \cdot \mathrm{mol}^{-1} \cdot \mathrm{K}^{-1}\right)$ represent the Gibbs free energy change, enthalpy change, and entropy change, respectively, $K_{c}$ is the equilibrium constant, and $C_{s}(\mathrm{mg} / \mathrm{L})$ is the concentration of the remaining $\mathrm{RhB}$ solution at equilibrium.

In the recyclability examination, the adsorption experiment was conducted at room temperature by immersing $10 \mathrm{mg}$ of LLHPC in $100 \mathrm{~mL}$ of $\mathrm{RhB}$ solution $(800 \mathrm{mg} / \mathrm{L})$ at $\mathrm{pH} 7$ and successively shaking for $12 \mathrm{~h}$, which was similar to the adsorption isotherm studies. The desorption experiment was performed by mixing the spent LLHPC with excess ethanol, shaking for $5 \mathrm{~min}$, and successively centrifuging for $15 \mathrm{~min}$ to separate LLHPC. The as-separated carbon was dried in an oven for $12 \mathrm{~h}$ at $120{ }^{\circ} \mathrm{C}$ to remove adsorbed ethanol. The comparison of LLHPC before and after dye adsorption is shown in the Supporting Information.

\section{ASSOCIATED CONTENT}

\section{Supporting Information}

The Supporting Information is available free of charge at https://pubs.acs.org/doi/10.1021/acsomega.0c02021.

SEM images, XRD patterns, $\mathrm{N}_{2}$ adsorption-desorption isotherm, and pore size distribution of as-obtained LLHPC after the adsorption of RhB molecules (PDF) 


\section{AUTHOR INFORMATION}

\section{Corresponding Author}

Huan Liu - College of Biological and Chemical Engineering, Anhui Polytechnic University, Wuhu 241000, PR China; (1) orcid.org/0000-0002-6443-7258; Phone: +86-05532871254; Email: huanhuan_1@126.com

\section{Authors}

Chao Xu - College of Biological and Chemical Engineering, Anhui Polytechnic University, Wuhu 241000, PR China

Yiming Ren - College of Biological and Chemical Engineering, Anhui Polytechnic University, Wuhu 241000, PR China

Dingxing Tang - College of Biological and Chemical Engineering, Anhui Polytechnic University, Wuhu 241000, PR China

Cuige Zhang - College of Biological and Chemical Engineering, Anhui Polytechnic University, Wuhu 241000, PR China

Fang Li - College of Biological and Chemical Engineering, Anhui Polytechnic University, Wuhu 241000, PR China

Xueling Wei - College of Biological and Chemical Engineering, Anhui Polytechnic University, Wuhu 241000, PR China

Chaofei Huo - College of Biological and Chemical Engineering, Anhui Polytechnic University, Wuhu 241000, PR China

Xingyang Li - College of Biological and Chemical Engineering, Anhui Polytechnic University, Wuhu 241000, PR China

Rongli Zhang - College of Biological and Chemical Engineering, Anhui Polytechnic University, Wuhu 241000, PR China

Complete contact information is available at:

https://pubs.acs.org/10.1021/acsomega.0c02021

\section{Notes}

The authors declare no competing financial interest.

\section{ACKNOWLEDGMENTS}

This work was funded by Introduction of talent research startup fund from the Anhui Polytechnic University (2018YQQ013) and Innovation training project for college students from Anhui Province (KC12020102).

\section{REFERENCES}

(1) Alatalo, S.-M.; Mäkilä, E.; Repo, E.; Heinonen, M.; Salonen, J.; Kukk, E.; Sillanpää, M.; Titirici, M.-M. Meso- and microporous soft templated hydrothermal carbons for dye removal from water. Green Chem. 2016, 18, 1137-1146.

(2) Hu, J.; Yu, H.; Dai, W.; Yan, X.; Hu, X.; Huang, H. Enhanced adsorptive removal of hazardous anionic dye "congo red" by a $\mathrm{Ni} / \mathrm{Cu}$ mixed-component metal-organic porous material. RSC Adv. 2014, 4, 35124-35130.

(3) Yang, Y.; Xie, Y.; Pang, L.; Li, M.; Song, X.; Wen, J.; Zhao, H. Preparation of Reduced Graphene Oxide/Poly(acrylamide) Nanocomposite and Its Adsorption of $\mathrm{Pb}(\mathrm{II})$ and Methylene Blue. Langmuir 2013, 29, 10727-10736.

(4) Yu, M.; Han, Y.; Li, J.; Wang, L. $\mathrm{CO}_{2}$-activated porous carbon derived from cattail biomass for removal of malachite green dye and application as supercapacitors. Chem. Eng. J. 2017, 317, 493-502.

(5) Wang, Z.; Wang, K.; Wang, Y.; Wang, S.; Chen, Z.; Chen, J.; Fu, $\mathrm{J}$. Large-scale fabrication of $\mathrm{N}$-doped porous carbon nanosheets for dye adsorption and supercapacitor applications. Nanoscale 2019, 11, 8785-8797.

(6) Liu, Q.; Gao, Y.; Zhou, Y.; Tian, N.; Liang, G.; Ma, N.; Dai, W. Highly Improved Water Resistance and Congo Red Uptake Capacity with a Zn/Cu-BTC@MC Composite Adsorbent. J. Chem. Eng. Data 2019, 64, 3323-3330.
(7) Allen, S. J.; Mckay, G.; Porter, J. F. Adsorption isotherm models for basic dye adsorption by peat in single and binary component systems. J. Colloid Interface Sci. 2004, 280, 322-333.

(8) Angin, D. Utilization of activated carbon produced from fruit juice industry solid waste for the adsorption of Yellow 18 from aqueous solutions. Bioresour. Technol. 2014, 168, 259-266.

(9) Gong, R.; Ye, J.; Dai, W.; Yan, X.; Hu, J.; Hu, X.; Li, S.; Huang, $\mathrm{H}$. Adsorptive Removal of Methyl Orange and Methylene Blue from Aqueous Solution with Finger-Citron-Residue-Based Activated Carbon. Ind. Eng. Chem. Res. 2013, 52, 14297-14303.

(10) Liew, R. K.; Azwar, E.; Yek, P. N. Y.; Lim, X. Y.; Cheng, C. K.; Ng, J.-H.; Jusoh, A.; Lam, W. H.; Ibrahim, M. D.; Ma, N. L.; Lam, S. $\mathrm{S}$. Microwave pyrolysis with $\mathrm{KOH} / \mathrm{NaOH}$ mixture activation: A new approach to produce micro-mesoporous activated carbon for textile dye adsorption. Bioresour. Technol. 2018, 266, 1-10.

(11) Saucier, C.; Adebayo, M. A.; Lima, E. C.; Cataluña, R.; Thue, P. S.; Prola, L. D. T.; Puchana-Rosero, M. J.; Machado, F. M.; Pavan, F. A.; Dotto, G. L. Microwave-assisted activated carbon from cocoa shell as adsorbent for removal of sodium diclofenac and nimesulide from aqueous effluents. J. Hazard. Mater. 2015, 289, 18-27.

(12) Urita, K.; Urita, C.; Fujita, K.; Horio, K.; Yoshida, M.; Moriguchi, I. The ideal porous structure of EDLC carbon electrodes with extremely high capacitance. Nanoscale 2017, 9, 15643-15649.

(13) Yao, L.; Yang, J.; Zhang, P.; Deng, L. In situ surface decoration of $\mathrm{Fe}_{3} \mathrm{C} / \mathrm{Fe}_{3} \mathrm{O}_{4} / \mathrm{C}$ nanosheets: Towards bi-functional activated carbons with supercapacitance and efficient dye adsorption. Bioresour. Technol. 2018, 256, 208-215.

(14) Wang, Y.; Song, Y.; Xia, Y. Electrochemical capacitors: mechanism, materials, systems, characterization and applications. Chem. Soc. Rev. 2016, 45, 5925-5950.

(15) Zhang, Y.; Yu, S.; Lou, G.; Shen, Y.; Chen, H.; Shen, Z.; Zhao, S.; Zhang, J.; Chai, S.; Zou, Q. Review of macroporous materials as electrochemical supercapacitor electrodes. J. Mater. Sci. 2017, 52, 11201-11228.

(16) Cazetta, A. L.; Pezoti, O.; Bedin, K. C.; Silva, T. L.; Paesano Junior, A.; Asefa, T.; Almeida, V. C. Magnetic Activated Carbon Derived from Biomass Waste by Concurrent Synthesis: Efficient Adsorbent for Toxic Dyes. ACS Sustainable Chem. Eng. 2016, 4, $1058-1068$.

(17) Maneerung, T.; Liew, J.; Dai, Y.; Kawi, S.; Chong, C.; Wang, C.-H. Activated carbon derived from carbon residue from biomass gasification and its application for dye adsorption: kinetics, isotherms and thermodynamic studies. Bioresour. Technol. 2016, 200, 350-359.

(18) Li, X.; Cao, W.-c.; Liu, Y.-g.; Zeng, G.-m.; Zeng, W.; Qin, L.; Li, T.-t. Property Variation of Magnetic Mesoporous Carbon Modified by Aminated Hollow Magnetic Nanospheres: Synthesis, Characterization, and Sorption. ACS Sustain. Chem. Eng. 2017, 5, 179-188.

(19) Shi, J.; Cui, H.; Xu, J.; Yan, N.; Liu, Y.; Zhang, S. One-step synthesis of highly porous nitrogen doped carbon from the direct pyrolysis of potassium phthalimide for $\mathrm{CO}_{2}$ adsorption. J. CO2 Util. 2020, 39, 101164-101169.

(20) Dong, Y.; Lin, H.; Qu, F. Synthesis of ferromagnetic ordered mesoporous carbons for bulky dye molecules adsorption. Chem. Eng. J. 2012, 193-194, 169-177.

(21) Cui, H.; Xu, J.; Shi, J.; Yan, N.; Liu, Y. Facile fabrication of nitrogen doped carbon from filter paper for $\mathrm{CO}_{2}$ adsorption. Energy 2019, 187, 115936

(22) Fechler, N.; Wohlgemuth, S.-A.; Jäker, P.; Antonietti, M. Salt and sugar: direct synthesis of high surface area carbon materials at low temperatures via hydrothermal carbonization of glucose under hypersaline conditions. J. Mater. Chem. A. 2013, 1, 9418-9421.

(23) Ghimire, P.; Gunathilake, C.; Wickramaratne, N. P.; Jaroniec, M. Tetraethyl orthosilicate-assisted synthesis of nitrogen-containing porous carbon spheres. Carbon 2017, 121, 408-417.

(24) Gu, W.; Sevilla, M.; Magasinski, A.; Fuertes, A. B.; Yushin, G. Sulfur-containing activated carbons with greatly reduced content of bottle neck pores for double-layer capacitors: a case study for pseudocapacitance detection. Energy Environ. Sci. 2013, 6, 24652476. 
(25) Li, Y.; Wang, G.; Wei, T.; Fan, Z.; Yan, P. Nitrogen and sulfur co-doped porous carbon nanosheets derived from willow catkin for supercapacitors. Nano Energy 2016, 19, 165-175.

(26) Shi, J.; Cui, H.; Xu, J.; Yan, N.; Liu, Y. Design and fabrication of hierarchically porous carbon frameworks with $\mathrm{Fe}_{2} \mathrm{O}_{3}$ cubes as hard template for $\mathrm{CO}_{2}$ adsorption. Chem. Eng. J. 2020, 389, 124459.

(27) Qu, L.; Liu, Y.; Baek, J.-B.; Dai, L. Nitrogen-Doped Graphene as Efficient Metal-Free Electrocatalyst for Oxygen Reduction in Fuel Cells. ACS Nano 2010, 4, 1321-1326.

(28) Basta, A. H.; Fierro, V.; El-Saied, H.; Celzard, A. 2-Steps KOH activation of rice straw: an efficient method for preparing high performance activated carbons. Bioresour. Technol. 2009, 100, 39413948.

(29) Yun, Y. S.; Cho, S. Y.; Shim, J.; Kim, B. H.; Chang, S.-J.; Baek, S. J.; Huh, Y. S.; Tak, Y.; Park, Y. W.; Park, S.; Jin, H.-J. Microporous Carbon Nanoplates from Regenerated Silk Proteins for Supercapacitors. Adv. Mater. 2013, 25, 1993-1998.

(30) Teng, Y.; Liu, E.; Ding, R.; Liu, K.; Liu, R.; Wang, L.; Yang, Z.; Jiang, H. Bean dregs-based activated carbon/copper ion supercapacitors. Electrochim. Acta 2016, 194, 394-404.

(31) Zhao, G.; Chen, C.; Yu, D.; Sun, L.; Yang, C.; Zhang, H.; Sun, Y.; Besenbacher, F.; Yu, M. One-step production of O-N-S co-doped three-dimensional hierarchical porous carbons for high-performance supercapacitors. Nano Energy 2018, 47, 547-555.

(32) Mondal, A. K.; Kretschmer, K.; Zhao, Y.; Liu, H.; Fan, H.; Wang, G. Naturally nitrogen doped porous carbon derived from waste shrimp shells for high-performance lithium ion batteries and supercapacitors. Micro. Mesopor. Mater. 2017, 246, 72-80.

(33) Yu, X.; Kang, Y.; Park, H. S. Sulfur and phosphorus co-doping of hierarchically porous graphene aerogels for enhancing supercapacitor performance. Carbon 2016, 101, 49-56.

(34) Liu, B.; Liu, Y.; Chen, H.; Yang, M.; Li, H. Oxygen and nitrogen co-doped porous carbon nanosheets derived from Perilla frutescens for high volumetric performance supercapacitors. J. Power Sources 2017, 341, 309-317.

(35) Ouyang, T.; Cheng, K.; Gao, Y.; Kong, S.; Ye, K.; Wang, G.; Cao, D. Molten salt synthesis of nitrogen doped porous carbon: a new preparation methodology for high-volumetric capacitance electrode materials. J. Mater. Chem. A 2016, 4, 9832-9843.

(36) Ghaedi, M.; Nasab, A. G.; Khodadoust, S.; Rajabi, M.; Azizian, S. Applications of activated carbons as the adsorbents for methylene blue removal: Kinetics and equilibrium studies. J. Ind. Eng. Chem. 2014, 20, 2317-2324.

(37) Ma, P.; Wang, S.; Wang, T.; Wu, J.; Xing, X.; Zhang, X. Effect of bifunctional acid on the porosity improvement of biomass-derived activated carbon for methylene blue adsorption. Environ. Sci. Pollut. Res. 2019, 26, 30119-30129.

(38) Fernandez, M. E.; Ledesma, B.; Román, S.; Bonelli, P. R.; Cukierman, A. L. Development and characterization of activated hydrochars from orange peels as potential adsorbents for emerging organic contaminants. Bioresour. Technol. 2015, 183, 221-228.

(39) Rozada, F.; Otero, M.; García, A. I.; Morán, A. Application in fixed-bed systems of dsorbents obtained from discarded tyres and sewage sludge. Dyes Pigm. 2007, 72, 47-56.

(40) Zhu, X.; Yu, S.; Xu, K.; Zhang, Y.; Zhang, L.; Lou, G.; Wu, Y.; Zhu, E.; Chen, H.; Shen, Z.; Bao, B.; Fu, S. Sustainable activated carbons from dead ginkgo leaves for supercapacitor electrode active materials. Chem. Eng. Sci. 2018, 181, 36-45.

(41) Deng, H.; Yang, L.; Tao, G.; Dai, J. Preparation and characterizations of activated carbons from cotton stalk by microwave-assisted chemical activation and its application in methylene blue adsorption. J. Hazard. Mater. 2009, 166, 1514-1521.

(42) Liou, T.-H. Development of mesoporous structure and high adsorption capacity of biomass-based activated carbon by phosphoric acid and zinc chloride activation. Chem. Eng. J. 2010, 158, 129-142.

(43) Wei, W.; Lu, R.; Xie, H.; Zhang, Y.; Bai, X.; Gu, L.; Da, R.; Liu, $\mathrm{X}$. Selective adsorption and separation of dyes from an aqueous solution on organic-inorganic hybrid cyclomatrix polyphosphazene submicro-spheres. J. Mater. Chem. A 2015, 3, 4314-4322. 